\title{
Classification and quantification of abnormal sperm along the epididymal tract. Comparison between adult and aged hamsters
}

\author{
A Calvo $^{1 *}$, E Martínez $^{2}$, LM Pastor $^{3 * *}, \mathrm{JM}$ Vázquez $^{2}, \mathrm{~J} \mathrm{Roca}^{2}$ \\ ${ }^{\prime}$ Department of Histology, Faculty of Medicine, University of Navarra, c/Irunlarrea s/n, \\ 31008 Pamplona; ${ }^{2}$ Department of Animal Pathology, Faculty of Veterinary Science, \\ University of Murcia, Espinardo, 30071 Murcia, ${ }^{3}$ Department of Cell Biology, \\ Faculty of Medicine, University of Murcia, Espinardo, 30071 Murcia, Spain
}

(Received 22 April 1997; accepted 5 November 1997)

\begin{abstract}
Summary - The types and averages of abnormal sperm were studied in the epididymis of adult and aged golden hamsters. Abnormal spermatozoa represent 14.6-19.6\% of the total of spermatozoa in adults, $31.7-42.1 \%$ in middled-aged hamsters, and $39.3-50 \%$ in advanced-aged hamsters. Twelve abnormal shapes were found, with the lack of an acrosome, the lack of a head, and the coiling of the tail, being the most frequent in the three age groups. An important increase in the number of coiled spermatozoa was found in the corpus and proximal cauda of the epididymis, but a decrease was observed in the distal cauda. Our data suggest that the epididymis produces secondary defects in spermatozoa running from the proximal caput to the middle zone of the duct, but that many of these spermatozoa are eliminated in the distal cauda. Such a result is mainly found in aged animals, in which a higher percentage of abnormal sperm from secondary origin is found with respect to adults.
\end{abstract}

epididymis / spermatozoa / ageing

Résumé - Classification et quantification des spermatozoïdes anormaux le long du conduit épididymaire. Comparaison entre hamsters adultes et vieux. Les types et pourcentages de spermatozoïdes anormaux dans l'épididyme des hamsters adultes et vieux ont été étudiés. Les spermatozoïdes anormaux représentent 14,6-19,6\% du total des spermatozoïdes chez les adultes, $31,7-42,1 \%$ chez les hamsters d'âge mûr et 39,3-50\% chez les hamsters en phase avancée de vieillissement. Douze formes anormales ont été identifiées. L'absence d'acrosome, l'absence de tête et l'enroulement de la queue sont les plus fréquents dans les trois groupes d'âge. On trouve une augmentation importante de spermatozoïdes enroulés dans le corpus et la cauda proximale de l'épididyme, et une réduction dans

\footnotetext{
* Correspondence

Fax: (34) 48-42 56 49; e-mail: acalvo@mail2.cti.unav.es

** Correspondence and reprints

Fax: (34) 68-36-41-50; e-mail: bioetica@fcu.um.es
} 
la cauda distale. Nos données montrent que l'épididyme produit des défauts secondaires chez les spermatozoïdes qui avancent depuis le caput proximal, jusqu'à la zone intermédiaire du conduit, beaucoup parmi eux sont éliminés dans la cauda distale. Ce phénomène est particulièrement important chez les vieux animaux, où l'on a trouvé un pourcentage supérieur de spermatozoïdes anormaux d'origine épididymaire par rapport aux animaux adultes.

épididyme / spermatozoïde / vieillissement

\section{INTRODUCTION}

The ejaculate of healthy adult males possesses an amount of abnormal spermatozoa (Mac Leod and Gold, 1951; Zamboni, 1987; Bonet, 1991). This amount varies among different species, and is caused by spermatogenic alterations of the testis (primary defects) or by the extragonadal organs, especially the epididymis, the so-called secondary defects (Barth and Oko, 1989; Bonet et al, 1992; Briz et al, 1996). Sperm abnormalities have been widely studied in man (David et al, 1975; Zamboni, 1987; Holstein et al, 1988; Dadoune, 1988) and in other mammals of interest, such as cattle (Barth and Oko, 1989; Bonet et al, 1992), but there is little information on rodents, despite the fact that are widely used in reproductive research (Working, 1988). Some studies in the mouse have focused mainly on head defects (Krzanowska, 1981; Krzanoswka et al, 1995). Morphological sperm aberrations related to passage through the epididymis have been studied in boar by Briz et al (1996). These authors found that spermatozoa with folded tail, coiled tail and with two fused tails, are associated with their passage through the epididymis. The presence in semen of coiled spermatozoa has also been described in relation to the epididymis in bulls (Barth and Oko, 1989).

There are several pathologies, genetic alterations and toxicants, which increase the average of altered spermatozoa, thus affecting fertility. Some examples are cryptorchidism (Plöen and Hakarsson, 1978), dyskinetic cilia syndrome (Zamboni, 1987), or mutagenic agents (Colie, 1993). Ageing causes a physiological dysfunction, which affects the reproductive organs (Vom Saal et al, 1994; Tsitouras and Bulat, 1995). In this way, failures in spermatogenesis [Paniagua et al (1991) in men; Horn et al (1996) in golden hamster], hormonal alterations (Gray, 1978; Tsitouras et al, 1982), and sexual inactivity (Vermeulen, 1979; Huber et al, 1980; Davidson et al, 1983) have been described. Aged males also present an increase in the percentage of abnormal ejaculated sperm (Krzanowska, 1981; Gosden et al, 1982; Bujan et al, 1988). We have previously studied by transmission electron microscopy the sperm defects in the caudal zone of the epididymis of adult and aged hamsters. Our results show that aged animals possess an important increase in the percentage of abnormal spermatozoa, but few types of new alterations (Calvo et al, 1995).

Therefore, the objectives of this study are: to describe the epididymal sperm alterations in adult and aged hamsters by light microscopy; to perform a quantification of these altered shapes in each zone of the epididymis, in order to evaluate the contribution of this organ to the development of secondary sperm defects; and to examine the effect of ageing in producing new or more abnormal shapes. We also study sperm viability, to examine necrospermy in relation with sperm alterations.

\section{MATERIALS AND METHODS}

Male hamsters (Mesocricetus auratus) were grown from birth to adulthood in the Animalar- 
ium of the University of Murcia. Three groups were established: adults ( 6 months old, $n=10$ ), middle-aged hamsters (18 months old, $n=10$ ), and aged (24 months, $n=5$ ). Food and water were given ad libitum, and light conditions were 14:10 light/darkness. At the appropriate age, the three groups of hamsters were killed by an overdose of pentobarbital. The epididymides were quickly removed, carefully cleaned with saline serum, cut with a sharp knife into proximal caput (zone I), distal caput (zone II), corpus (zone III), proximal cauda (zone IV), and distal cauda (zone $\mathrm{V})$, and put into Petri dishes ( $3.5 \mathrm{~mm}$ in diameter) containing PBSDm (modified Dulbecco's phosphate buffer saline). To avoid the spermatozoa undergoing osmotic shock (Kann and Serres, 1980; Serres and Kann, 1984), the PBSDm was adjusted according to the different conditions required for caput ( $400 \mathrm{mOsm} / \mathrm{kg}$ ), corpus (375 mOsm/ $\mathrm{kg}$ ), and cauda ( $290 \mathrm{mOsm} / \mathrm{kg}$ ). Tissues were then carefully macered, and Petri dishes were placed on a stirring and hot plate $\left(37^{\circ} \mathrm{C}\right)$. After $10 \mathrm{~min}$ agitation, aliquots of $50 \mu \mathrm{L}$ were taken and nigrosin-eosin stain was developed to count the percentage of spermatozoa with membrane integrity (viable spermatozoa). Two hundred spermatozoa per zone and per animal were counted. A further $50 \mu \mathrm{L}$ of the suspension were taken and mixed with $50 \mu \mathrm{L}$ of $2.5 \%$ glutaraldehyde (buffered in $0.1 \mathrm{M}$ sodium cacodylate). Spermatozoa were observed after $30 \mathrm{~min}$ in the fixative solution with a phase contrast miroscope (Nikon). Photographs were taken with a Zeiss photomicroscope equipped with Nomarski optic system.

Two hundred spermatozoa per epididymal zone, and per animal were counted and classified. For quantitation of each type of abnormality, spermatozoa were grouped into classes of frequencies. Abnormal shapes that exceeded $1 \%$ of the total of spermatozoa in the group of adult hamsters were considered as a class. Those with a frequncy lower than $1 \%$ were included in the class 'other abnormalities'. Data were expressed as percentages. The total percentage of abnormal shapes was also evaluated.

For statistical treatment, each class of spermatozoa was considered as a variable. A oneway ANOVA analysis was performed, completed with Student's $t$-test, to compare: a) differences between the epididymal zones (in each age group); and b) differences between ages (in each epididymal zone).

\section{RESULTS}

\section{Sperm morphology}

\section{Qualitative analysis}

The type of spermatozoon with a normal morphology is shown in fig la, No 1. Different abnormal spermatozoa were found in the epididymis of the hamster, some appearing only in aged animals. The following alterations were found in the head. a) Without acrosome (fig 1a, No 2; and fig 2). b) Without head (fig 1a, No 3). c) Spermatozoa finished in a double peak (fig 1a, No 4; and fig 3). d) Spermatozoa with an abnormal curvature of the head (fig 1a, No 5). e) Spermatozoa with non-falciform head. Sperm with this alteration usually had mace-shaped heads (fig 1a, No 6). f) Double-headed spermatozoa (fig 1b, No 7; and fig 4). g) Spermatozoa joined at the head (fig 1b, No 8; and fig 5).

Shapes a-e, were observed in all the epididymal zones of both adult and aged hamsters. Shapes $\mathrm{f}$ and $\mathrm{g}$ were seen only in aged hamsters, especially in 24-month-old animals, in all the zones of the epididymis.

The following alterations were found in the tail. $h$ ) Coilings or bendings of the tail (fig 1b, Nos 9-12; figs 6 and 7). Coilings could be found at different levels of the sperm tail. Some spermatozoa had a ringshape (fig 1b, No 9). Some characteristic and abundant bendings were seen in the zone of Jensen's ring involving the cytoplasmic droplet (fig lb, No 10). Many sperm flagelli were also bent at the principal piece (fig $1 \mathrm{~b}$, Nos 11 and 12). These defects were seen in the three age groups. i) Double-tailed spermatozoa (fig 1c, No 13). This was an infrequent alteration observed only in aged hamsters (especially in 24-month-old animals). j) Spermatozoa with a branched intermediate piece (fig 1c, No 14; and fig 8). These spermatozoa were rarely found in 


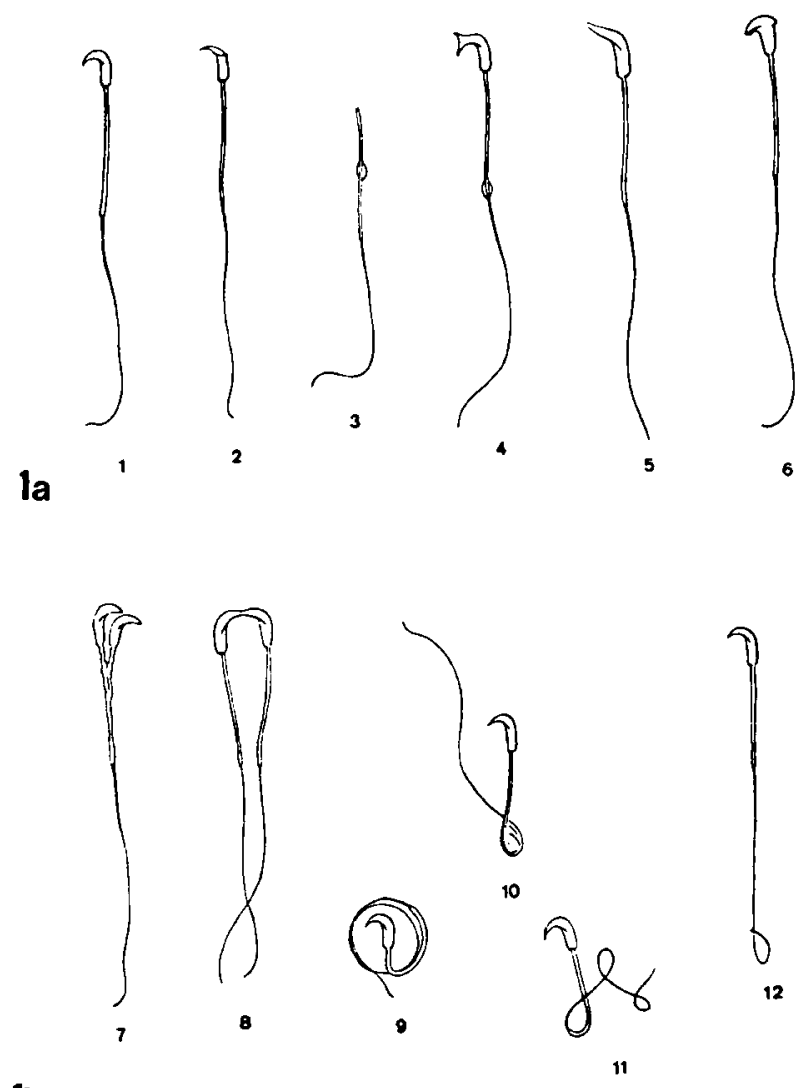

lb

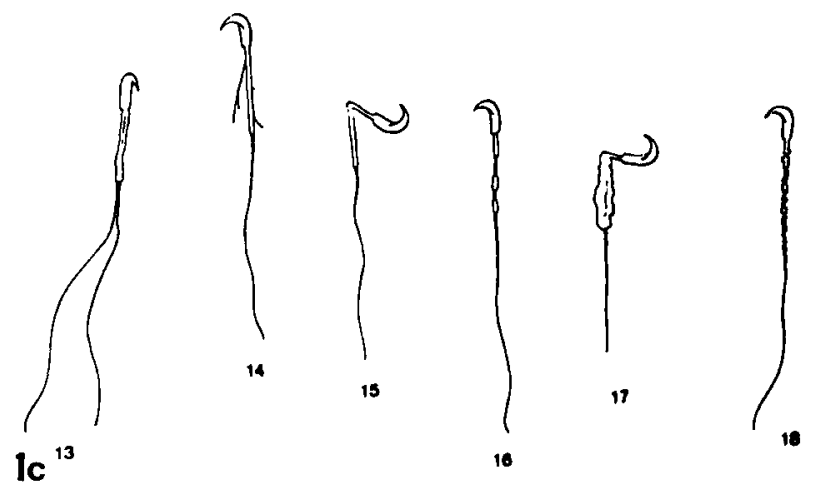

Fig 1. (a) Morphologic shapes of epididymal sperm: No 1, sperm with normal morphology; Nos 2-6, sperm with head alterations. (b) Altered sperm in head (Nos 7 and 8) or tail (9-12). Numbers 7 and 8 were only seen in aged hamsters. (c) Different altarations in the tail sperm. Number 13 was only observed in aged hamsters. 

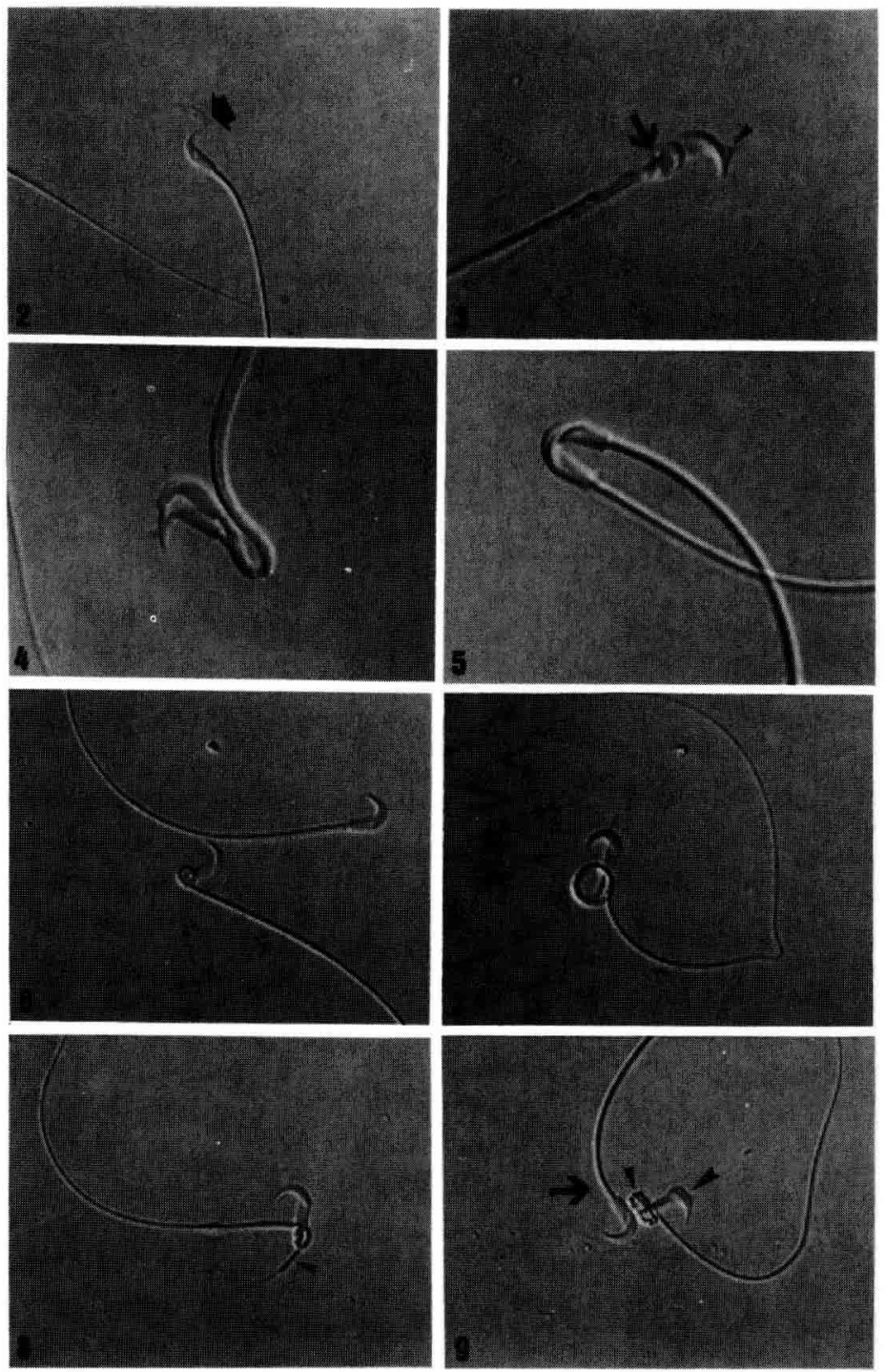

Fig 2. Spermatozoon without acrosome (arrow).

Fig 3. Spermatozoon with irregular head in the postacrosomal region (arrow), and acrosomal region (arrowhead), finished in a double peak.

Fig 4. Abnormal shape with two heads.

Fig 5. Spermatozoa joined at the heads.

Fig 6. Coiling of the sperm tail at the level of the neck.

Fig 7. Coiling of the sperm tail involving the intermediate piece.

Fig 8. Spermatozoon with a branched intermediate piece (arrowhead).

Fig 9. Abnormal shape presenting irregular head (great arrowhead) and tail (small arrowhead), together with a normal sperm (arrow). 
adult hamsters, being more abundant in aged animals. k) Folded spermatozoa (fig lc, No 15). Foldings of the sperm were more frequent at the level of the intermediate piece but were also observed in the principal piece. They were rarely seen in adults. I) Irregular intermediate piece (fig 1c, Nos 16-18). Some spermatozoa had thin zones in their intermediate piece, whereas others had their normal width (fig 1c, No 16). Some spermatozoa presented extremely wide and irregular intermediate pieces (fig 1c, No 17). Sometimes only a part of the intermediate piece had this alteration (fig 9) whilst at others the intermediate piece was thinner, with an irregular shape (fig 1c, No 18). These alterations were found in all the groups, but especially in 24 -month-old hamsters.

\section{Quantitative analysis}

In adult hamsters, the averages of abnormal spermatozoa were: $17.5 \pm 1.6 \%$ (zone I), $17 \pm 1.85 \%$ (in zone II), $19.6 \pm 2.1 \%$ (in zone III), $19.5 \pm 2.6 \%$ (in zone IV), and 14.6 $\pm 1.7 \%$ (in zone V). Zonal differences are shown in figure 10 . In this study, 18-monthold hamsters had significantly $(P<0.05)$ higher values: from $31.7 \pm 1.3 \%$ in the distal cauda, to $42.1 \pm 2.9 \%$ in the distal caput. However, 24-month-old hamsters presented the highest values: from $39.2 \pm 1.3 \%$ in the proximal caput, to $50 \pm 5.8 \%$ in the corpus. Zonal differences and differences between age groups are shown in figure 10.

As explained in Materials and methods, with respect to each type of alteration, we only considered for statistical treatment those classes of spermatozoa which presented a frequency higher than $1 \%$ of the total of sperm in adults. The classes found were the following: a) spermatozoa without acrosome; b) headless spermatozoa; c) coiled spermatozoa at any part of the tail; and $\mathrm{d}$ ) other abnormalities (this group is composed of the remaining sperm defects classified above).

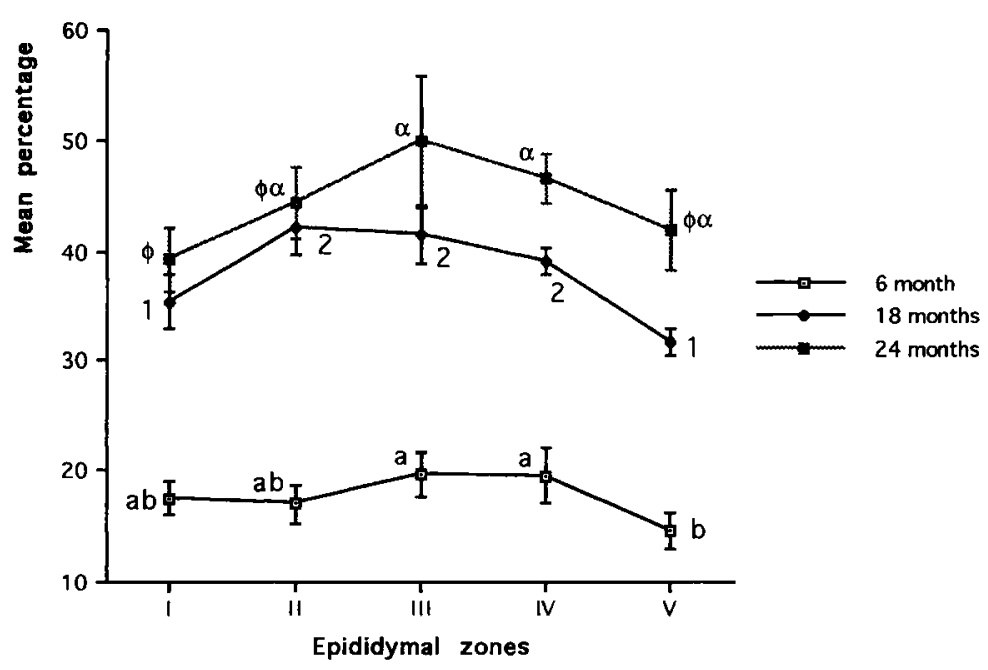

Fig 10. Mean percentage of total abnormal spermatozoa ( \pm SEM) in each epididymal zone and in each age group. Differences $(P<0.05)$ between zones are expressed as different letters ( 6 months), numbers $(18$ months) or greek letters $(24$ months). Differences $(P<0.05)$ between ages: 6 versus 18 months, 6 versus 24 months (both in all the zones), 18 versus 24 months (in zones IV and V). I: proximal caput. II: distal caput. III: corpus. IV: proximal cauda. V: distal cauda. 


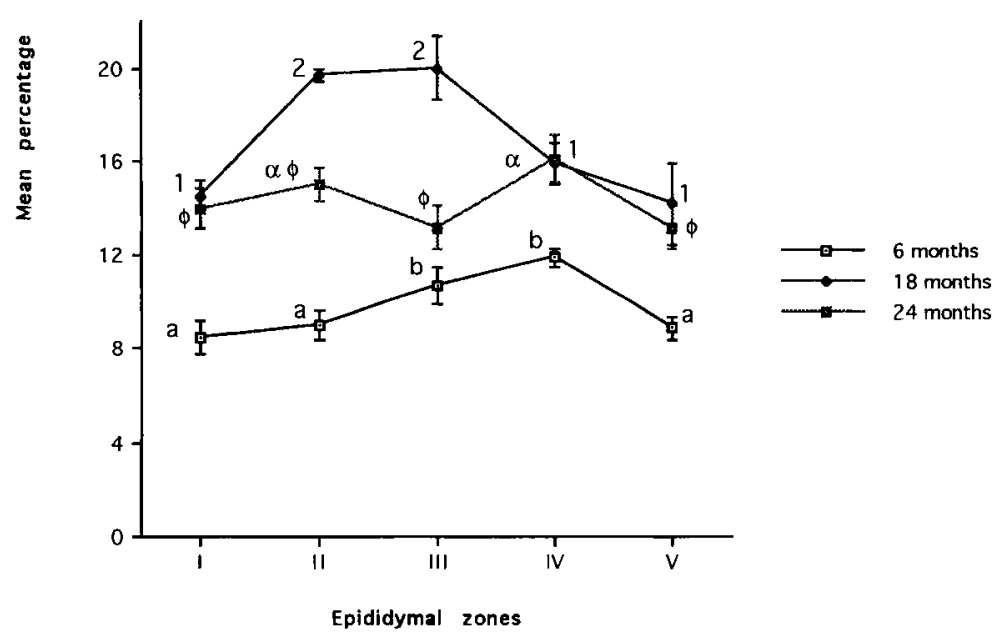

Fig 11. Mean percentage of spermatozoa without acrosome ( \pm SEM) in each epididymal zone and in each age group. Differences $(P<0.05)$ between zones are expressed as different letters $(6$ months), numbers $(18$ months) or greek letters ( 24 months). Differences $(P<0.05)$ between ages: 6 versus 18 months, 6 versus 24 months (both in all the zones), 18 vs 24 months (in zones II and III) I: proximal caput. II: distal caput. III: corpus. IV: proximal cauda. V: distal cauda.

a) Spermatozoa without acrosome: figure 11 summarizes the results obtained. Adult hamsters had averages within the range of $8.5 \pm 0.7 \%$ (in zone I) to 11.9 $\pm 0.4 \%$ (in zone IV). Aged animals had a significant $(P<0.05)$ increase in the percentage of this defect, with respect to adults, in all the zones of the duct. It was found that 18-month-old hamsters had values from 14.2 $\pm 1.7 \%$ (zone V) to $20 \pm 1.4 \%$ (zone III), while 24 -month-old hamsters showed values from $13.2 \pm 0.9 \%$ (in the distal cauda) to $16.1 \pm 1 \%$ (in the proximal cauda). Differences between epididymal zones and between age groups are shown in figure 11 .

b) Headless spermatozoa: the highest values were found in the proximal caput (zone I) in the three groups (fig 12). There was a progressive decrease in frequency of this alteration from zone I to zone V. In this study, 6-month-old hamsters showed 4.8 $\pm 0.4 \%$ in zone $I$, and $1.2 \pm 0.4 \%$ in zone $\mathrm{V} ; 18$-month-old hamsters had $10.5 \pm 0.9 \%$ in zone I, and $2.5 \pm 0.2 \%$ in zone $\mathrm{V}$; and 24-month-old animals presented $9.8 \pm 0.6 \%$ in zone $\mathrm{I}$, and $2.5 \pm 0.1 \%$ in zone V. Both groups of 18- and 24-month-old animals showed significantly higher values than those of adults $(P<0.05)$. Differences between the groups of 18- and 24-monthold hamsters were found in zones II and III (see fig 12).

c) Coiled spermatozoa: this type of sperm defect increased from zone I to zones III and IV in all the groups, but most drastically in aged hamsters (fig 13). A decrease in their percentages was found in the distal cauda (zone V). Adult hamsters had in zone IV the highest value: $6.4 \pm 0.4 \%$. Zone $\mathrm{V}$ presented the lowest value: $2.8 \pm 0.2 \%$. The caput epididymis showed $3.3 \pm 0.2 \%$ and $4.8 \pm 0.2 \%$, for zones I and II, respectively. Zone III presented $6.1 \pm 0.6 \%$. A significant increase in 18- and 24-month-old animals was observed with respect to adults. In both these groups, the increase in the cor- 


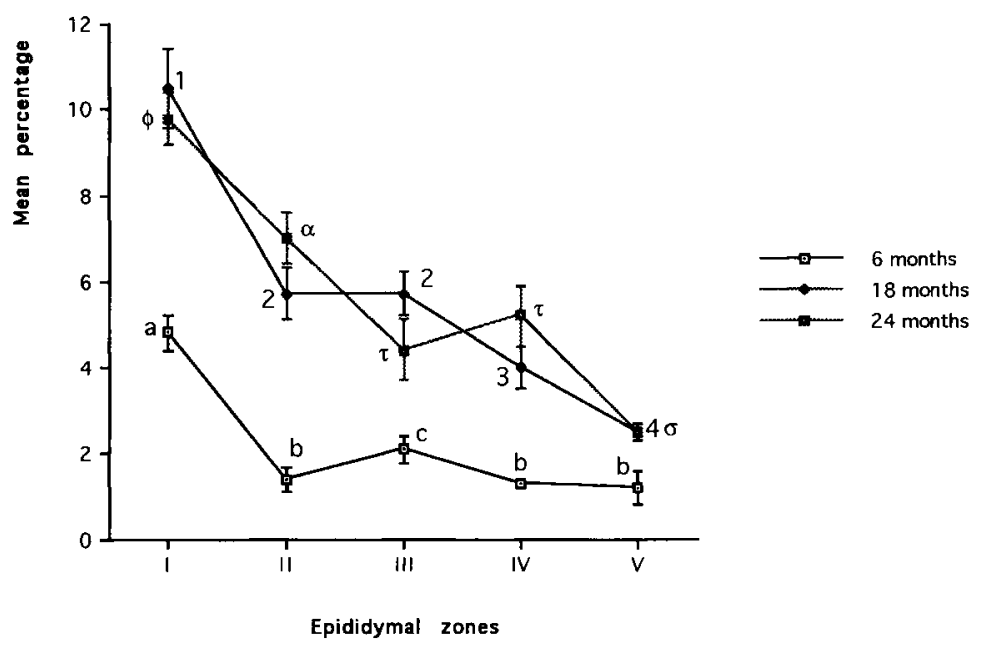

Fig 12. Mean percentage of headless spermatozoa ( \pm SEM) in each epididymal zone and in each age group. Differences $(P<0.05)$ between zones are expressed as different letters ( 6 months), numbers $(18$ months) or greek letters $(24$ months). Differences $(P<0.05)$ between ages: 6 versus 18 months, 6 versus 24 months (both in all the zones), 18 versus 24 months (in zones II, and III). I: proximal caput. II: distal caput. III: corpus. IV: proximal cauda. V: distal cauda.

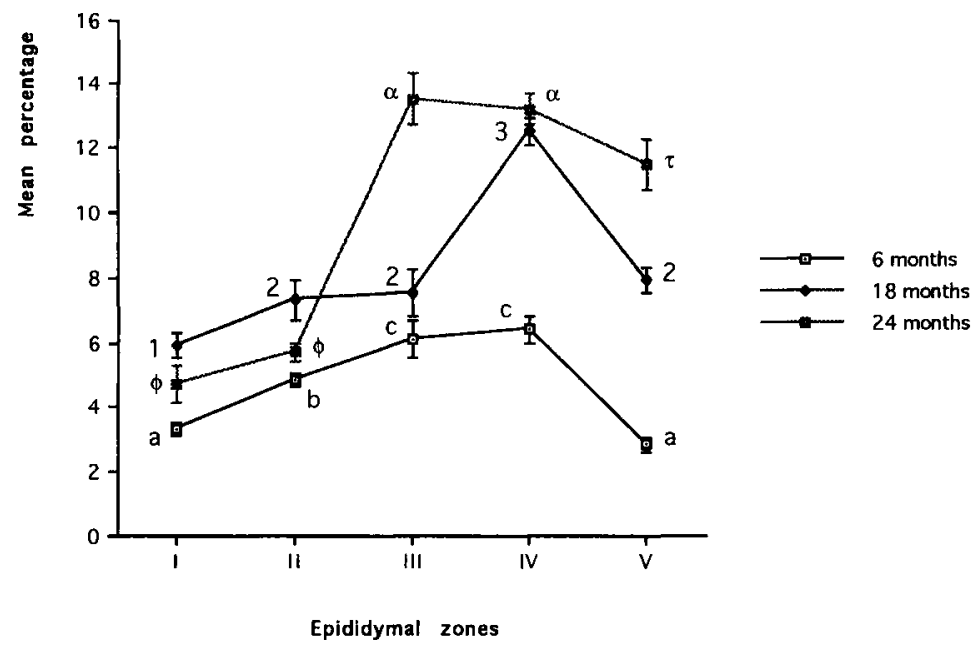

Fig 13. Mean percentage of coiled spermatozoa $( \pm S E M)$ in each epididymal zone and in each age group. Differences $(P<0.05)$ between zones are expressed as different letters ( 6 months), numbers (18 months) or greek letters ( 24 months). Differences $(P<0.05)$ between ages: 6 versus 18 months, 6 versus 24 months (both in all the zones), 18 versus 24 months (in zones I, II, III, and V). I: proximal caput. II: distal caput. III: corpus. IV: proximal cauda. V: distal cauda. 


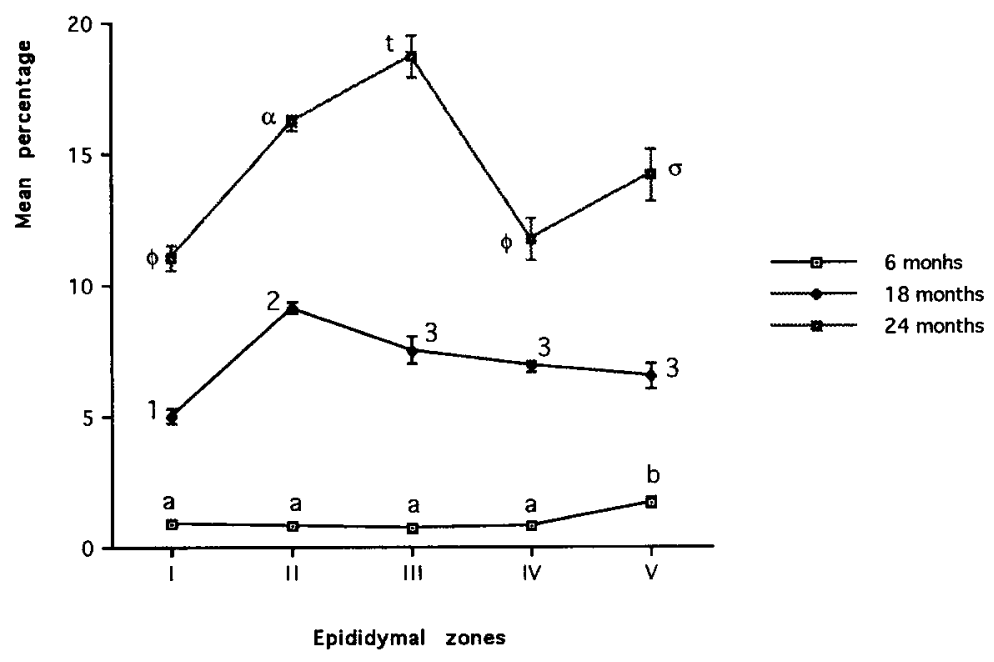

Fig 14. Mean percentage of other abnormalities ( \pm SEM) in each epididymal zone and in each age group. Differences $(P<0.05)$ between zones are expressed as different letters ( 6 months), numbers (18 months) or greek letters ( 24 months). Differences $(P<0.05)$ between ages: 6 versus 18 months, 6 versus 24 months, 18 versus 24 months (the three groups in all the zones). I: proximal caput. II: distal caput. III: corpus. IV: proximal cauda. V: distal cauda.

pus and/or proximal cauda was greater than in adults (see fig 13).

Other abnormalities: this class presented in adults the following averages: $0.9 \pm 0.1 \%$, $0.8 \pm 0.1 \% ; 0.7 \pm 0.1 \% ; 0.8 \pm 0.1 \%$; and $1.7 \pm 0.2 \%$, for zones I, II, III, IV and V, respectively. Here, 18-month-old hamsters showed a $5-10$ fold increase in values in comparison to adults, and 24-month-old hamsters a 10-20 fold increase with regard to adults. Data and significant differences between zones and age groups are shown in figure 14 .

\section{Sperm viability}

Data on viable sperm are shown in figure 15. Adult hamsters had the highest values: from $68 \pm 2.8$ in the distal cauda, to $73 \pm 2$ in the proximal caput. No significant differences were seen between epididymal zones. Both groups of aged hamsters had lower values: 18 -month-old hamsters had values from $52.5 \pm 2.8$ in the corpus, to 58.3 \pm 1.6 in the proximal caput, and 24 -monthold hamsters, values from $53.5 \pm 5.1$ in the proximal cauda, to $62.5 \pm 2.3$ in the proximal caput. No zonal differences were observed in either group. A significant decrease $(P<0.05)$ was found in 18 - and 24-month-old hamsters, with respect to adults, but no statistical differences were seen between both groups of aged hamsters.

\section{DISCUSSION}

From a qualitative point of view, we have distinguished 12 abnormal shapes, three of which were seen exclusively in aged hamsters (ie, double-headed, linked by their heads, and double-tailed spermatozoa). The pattern of abnormalities is similar to that 


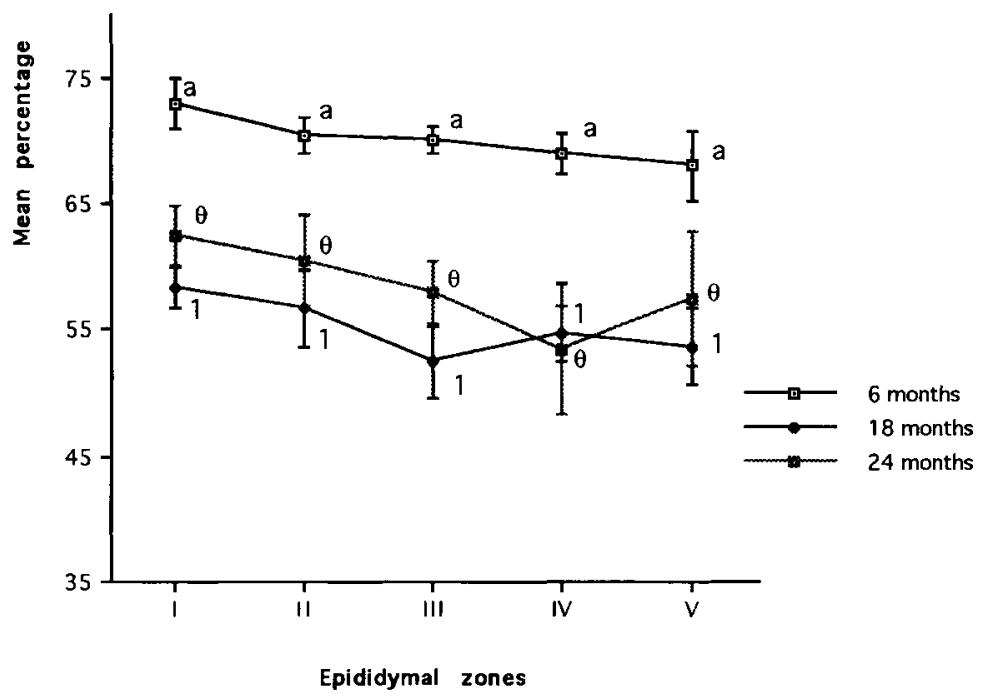

Fig 15. Mean percentage of viable spermatozoa ( \pm SEM) in each epididymal zone and in each age group. Differences $(P<0.05)$ between zones are expressed as different letters $(6$ months), numbers (18 months) or greek letters ( 24 months). Differences $(P<0.05)$ between ages: 6 vs 18 months, 6 vs 24 months (both in all the zones). I: proximal caput. II: distal caput. III: corpus. IV: proximal cauda. $\mathrm{V}$ : distal cauda.

found in other species, for instance man (David et al, 1975; Holstein et al, 1988; Dadoune, 1988), bull (Barth and Oko, 1989), and boar (Bonet, 1991; Bonet et al, 1992; Briz et al, 1996). Although the abnormal shapes we have found exclusively in aged hamsters have been described in adults in other species, they normally represent a very small percentage of sperm: in humans, double-headed sperm account for $0.8 \%$, and double-tailed sperm $0.5 \%$ of the total number of spermatozoa (Schwartz et al, 1984). The presence of sperm with macrocephalic, microcephalic and duplicate heads has been commonly found in adult men (Dadoune, 1988; Bujan et al, 1988) and in other mammals (Curry et al, 1989; Bonet, 1991). Bujan et al (1988) found that aged men presented a significant increase in these sperm alterations. We have not observed such a type of defective sperm in hamster.
Quantitatively, we found three predominant types of sperm defects, both in adult and aged hamsters: lack of the acrosome, headless and coilings of the tail. The remaining defects, included in the class 'other abnormalities', are quantitatively of little importance in adult hamsters, although such importance is much greater in aged animals (mainly in those of 24 months). Present results show that, at least in the hamster, ageing produces an increase in the frequency of altered sperm more than an increase in the appearance of new kinds of alterations. Such a result is consistent with our previous ultrastructural data on abnormal spermatozoa from cauda epididymis of adult and aged hamsters (Calvo et al, 1995).

Those spermatozoa which have lost their acrosome in the epididymis probably die in their passage through the excurrent duct, or in the female tract. This is one of the most 
common alterations found in the ejaculates of many species (Barth and Oko, 1989; Ali and Grimes, 1989; Bonet, 1991). The precise origin of this defect is still unclear, but it has been observed in some cases as a result of acrosomal agenesia in the testis (Baccetti et al, 1977). Unfavourable conditions in the osmolarity of the sperm fluid may also cause a false acrosome reaction (Cooper, 1986). In this way, a dysfunction in the turnover of the epididymis could lead to an increase in this abnormality. In our study, the average of reacted sperm tended to increase from the caput towards the intermediate zone of the duct (zones III and IV, see fig 11). In the distal cauda (zone V) the average decreased to values similar to that found in the proximal caput.

Observations with transmission electron microscopy have revealed that decapitation is the result of an abnormal connection between the sperm head and tail in spermiogenesis (Perotti et al, 1981). We have found, in the three age groups, that the highest percentage of decapitated sperm is present in the caput epididymis, with a gradual decrease towards the cauda (see fig 12). These broken spermatozoa may be destroyed by luminal enzymes, and absorbed by the epithelium, as suggested by Cooper and Hamilton (1977) for the caudal zone. Another possible explanation for this result could be that spermatozoa suffered damage during the process of manipulation. The proteins of the neck of immature spermatozoa from the caput epididymis possess a lower amount of disulphure bonds than those of mature spermatozoa from cauda (Cooper, 1986). Thus, manipulation during sperm recovery could cause fractures in the neck of immature sperm.

Few abnormalities apparently occur after spermiation (Dadoune, 1988). Coiling of sperm tail, bendings and persistence of the cytoplasmic droplets have been the alterations most consistently linked to the epididymis secondary defects (Koefoed-
Johnsen and Pedersen, 1971; Ali and Grimes, 1989; Barth and Oko, 1989; Bonet et al, 1992). Briz et al (1996) have also described in boars that spermatozoa with two fused tails may have their origin in the epididymal corpus. In the adult hamster we have found an increase in the frequency of coiled sperm from the caput to the proximal cauda. This result is also found in senile animals, but the increase in the corpus and proximal cauda is higher than that of adults. Nevertheless, in both cases, this average is substantially diminished in zone $\mathrm{V}$ (distal cauda) (see fig 13). These data suggest a possible influence of the epididymis on the appearance of coiled sperm (especially in aged hamsters) in the middle zone of the duct, but a subsequent elimination of the altered shapes in the distal cauda.

If the total average of aberrant sperm is considered, adult hamsters present few differences between epididymal zones; but in aged animals, a similar tendency to that observed for acrosome-less (fig 11), and for coiled spermatozoa (fig 13) is found: an increase in the corpus and proximal cauda, but a decrease in the distal cauda (see fig 10). Taken together, these results are consistent with those reported by Cooper and Hamilton (1977) regarding the possible role of the distal cauda (zone for storage) in the destruction and phagocytosis of altered sperm in many mammals, including the hamster Mesocricetus auratus.

Some sperm could be seen as abnormal, as a consequence of necrospermy. Our results of viability show that there are no statistical differences between epididymal zones, both in adult and aged hamsters. These data probably indicate that the epididymis does not contribute significantly to the increase in dead spermatozoa, despite it producing abnormal shapes. Thus, both variables (necrospermy and teratospermy) seem not to be related.

Some types of defective sperm prevent fertilization if they are present in high pro- 
portions in semen (Zamboni, 1987; Barth and Oko, 1989). Nevertheless, except for the cases of severe teratozoospermy, the relationship between abnormal shapes and fertility has still not been definitively elucidated (Davis and Gravance, 1994). In our study, the percentage of altered sperm was approximately 20 , and $30-50 \%$ in adult and aged hamsters, respectively. Generally, rodents possess fewer aberrant forms than men (Working, 1988); adult men are not considered to have a fertility problem until the frequency of the cells exceeds $50 \%$ of the spermatozoa (Overstreet, 1984). In a study in the hamster, from the period of prepuberty to that of adulthood, Weissenberg et al (1987) observed a positive correlation between sperm alteration and fertility. In mice, Krzanowska et al (1995) failed to find a clear link between head sperm alterations and fertility. Zenick and Clegg (1989) observed that, at least in rats, the average level of abnormal sperm had to reach $90 \%$ in order to affect the size of the progeny. We have proven that the aged hamsters used in our study were fertile (unpublished observations), although we have not exhaustively tested the fertility of the animals with respect to the number of descendents and frequency of breeding.

New studies are needed to investigate the influence of defective sperm in fertility, and what is the threshold of normal spermatozoa in an ejaculate for a succesful fertilization. Besides, the knowledge of the precise origin of sperm malformations will help in the diagnosis, and possible therapy for some infertility problems.

\section{ACKNOWLEDGMENT}

The help in the statistical treatment by M Canteras is gratefully acknowledged.

\section{REFERENCES}

Ali JI, Grimes EM (1989) Sperm morphology: unstained and stained smears in fertile and infertile men. Arch Androl 22, 191-195

Baccetti B, Renieri T, Rosati F, Selmi MG, Casanova $S$ (1977) Further observations on the morphogenesis of the round headed human spermatozoa. Andrologia 9,255-264

Barth AD, Oko RJ (1989) Abnormal Morphology of Bovine Spermatozoa. Iowa State Univ Press, Ames IA, USA

Bonet S (1991) New data on aberrant spermatozoa in the ejacultae of Sus domesticus. Theriogenology $35,725-730$

Bonet S, Briz M, Fradera A, Egozcue J (1992) Origin, development and ultrastructure of boar spermatozoa with folded tails and with two tails. Hum Reprod 7, 523-528

Briz MD, Bonet S, Pinart B, Camps R (1996) Sperm malformations throughout the boar epididymal duct. Anim Reprod Sci 43, 221-239

Bujan L, Mieusset R, Mondinat Ch, Mansat A, Pontonnier F (1988) Sperm morphology in fertile men and its age related variation. Andrologia 20, 121 128

Calvo A, Pastor LM, Gallego-Huidobro J, Horn R, Pallares $J$ (1995) Abnormal spermatozoa in the cauda epididymidis of adult and aged hamsters (Mesocricetus auratus). An electron microscopic study. Acta Anat 154, 186-195

Colie CF (1993) Male mediated teratogenesis. Reprod Toxicol 7, 3-9

Cooper TG (1986) The Epididymis, Sperm Maturation and Fertilization. Springer Ver]ag, Berlin, Germany

Cooper TG, Hamilton DW (1977) Observations on destruction of spermatozoa in the cauda epididymis and proximal vas deferens of non-seasonal male mammals. Am J Anat 149, 93-100

Curry PT, Ziemer T, Van der Horst G, Burgess W, Straley M, Atherton RW, Kitchin RM (1989) A comparison of sperm morphology and silver nitrate staining characteristics in the domestic ferret and the black-footed ferret. Gamete Res 22, 27-36

Dadoune JP (1988) Ultrastructural abnormalities of human spermatozoa. Hum Reprod 3, 311-318

David G, Bisson JP, Czyglik F, Jouannet P, Gernigon C (1975) Anomalies morphologiques du spermatozoîde humain. 1. Propositions pour un système de classification. I Gynaecol Obstet Biol Reprod $4,17-36$

Davidson JM, Gray GD, Smith ER (1983) The sexual psychoendocrinology of aging. In: Neuroendocrinology of Aging (J Meites, ed), Plenum Press, New York, 221-258 
Davis RO, Gravance CG (1994) Consistency of sperm morphology classification methods. J Androl 15, 83-91

Gosden RG, Richardson DW, Brown N, Davidson DW (1982) Structure and gametogenic potential of seminiferous tubules in ageing mice. $J$ Reprod Fertil 64 , 127-133

Gray DG (1978) Changes in the levels of luteinizing hormone and testosterone in the circulation of aging male rats. $J$ Endocrinol 76, 551-552

Holstein AF, Roosen-Runge EC, Schirren C (1988) Ilustrated Pathology of Human Spermatogenesis. Grosse, Berlin, Germany

Horn R, Pastor LM, Moreno E, Calvo A, Canteras M, Pallares J (1996) Morphological and morphometric study of early changes in the ageing golden hamster testis. J Anat 188, 109-117

Huber MH, Bronson FH, Desjardins C (1980) Sexual activity of the aged male mice: correlation with level of arousal, physical endurance, pathological status and ejaculatory capacity. Biol Reprod 23, 305-316

Kann ML, Serres C (1980) Development and initiation of sperm motility in the hamster epididymis. Reprod Nutr Develop 20, 1739-1749

Koefoed-Johnsen HH, Pedersen H (1971) Further observations on the Dag defect of the tail of the bull spermatozoon. $J$ Reprod Fertil 26, 77-83

Krzanowska H (1981) Sperm head abnormalities in relation to the age and strain of the mice. $J$ Reprod Fertil 62, 385-392

Krzanowska H, Styrna J, Wabik-Sliz B (1995) Analysis of sperm quality in recombinant inbred mouse strains: correlation of sperm head shape with sperm abnormalities and with the incidence of supplementary spermatozoa in the periviteline space. $J$ Reprod Fertil 104, 347-354

Mac Leod J, Gold RZ (1951) The male factor in fertility and infertility. IV. Sperm morphology in fertile and infertile marriage. Fertil Steril 2, 394-414

Overstreet JW (1984) Laboratory tests for human male reproductive risk assessment. Teratog Carcinog Mutagen 4, 67-82

Paniagua R, Nistal M, Sáez FJ, Fraile B (1991) Ultrastructure of the aging human testis. $J$ Electron Microsc Tech 19, 241-260
Perotti MM, Giarola A, Gioria M (1981) Ultrastructural study of the decapitated sperm defect in an infertile man. J Reprod Fertil 63, 543-549

Plöen L N, Hakarsson N (1978) Abnormal epididymal spermatozoa two to thirty-five days after a brief experimental cryptorchidism in the rabbit. Int $J$ Androl 1, 250-261

Schwartz D, Mayaux MJ, Guihard-Moscato ML, Spira A, Jouannet P, Czyglik F, David G (1984) Study of sperm morphologic characteristics in a group of 833 fertile men. Andrologia 16, 413-428

Serres C, Kann ML (1984) Motility induction in hamster spermatozoa from caput epididymis: effects of forward motility protein (FMP) and calmodulin inhibitor Reprod Nutr Develop 24, 81-84

Tsitouras O, Bulat T (1995) The aging male reproductive system. Endocrine aspects of aging. Endocrinology and Metabolism Clinics of North America 24, 297-315

Tsitouras PD, Martin CE, Harman SM (1982) Relationship of serum testosterone to sexual activity in healthy elderly men. $J$ Gerontol $37,288-293$

Vermeulen A (1979) Decline in sexual activity in aging men: correlation with sex hormone levels and testicular changes. J Biosociol Sci 6, 5-18

Vom Saal F, Finch CE, Nelson JF (1994) Natural history and mechanisms of reproductive aging in humans, laboratory rodents, and other selected bertebrates. In: The Physiology of Reproduction, 2nd ed (E Knobil, J Neill, eds), Raven Press, New York, USA, ch 61

Weissenberg R, Bella R, Lunenfeld B (1987) The fertilizing capacity of golden hamster epididymal spermatozoa in relation to age, number, motility and morphology. Andrologia 19, 47-53

Working PK (1988) Male reproductive toxicology: comparison of the human to animal models. Environ Health Persp 77, 37-44

Zamboni L (1987) The ultrastructural pathology of the spermatozoon as a cause of infertility: the role of electron microscopy in the evaluation of semen quality. Fert Steril 48, 711-734

Zenick H, Clegg DE (1989) Assessment of male reproductive toxicity: a risk assessment approach. In: Principles and Methods of Toxicology (AW Hayes, ed), Raven Press, New York, USA 